\title{
LUEM PUA RICE EXTRACT ATTENUATES THE SEVERITY OF DEXTRAN SULFATE SODIUM- INDUCED ULCERATIVE COLITIS IN RATS THROUGH CHOLINOMIMETIC EFFECTS
}

\author{
KORNSUDA THIPART ${ }^{1}$, KUTCHARIN PHUNIKHOM ${ }^{1}$, ACHARAPORN NA LAMPANG NOENPLAB ${ }^{2}$, \\ JINTANA SATTAYASAI ${ }^{1 *}$
}

${ }^{1}$ Department of Pharmacology, Faculty of Medicine, Khon Kaen University, Thailand. ${ }^{2}$ Phitsanulok Rice Research Center, Wang Thong, Phitsanulok, Thailand. Email: sjinta@kku.ac.th

Received: 02 December 2019, Revised and Accepted: 31 October 2020

ABSTRACT

Objective: The objective of the study was to investigate the effect of aqueous extract of unpolished dark purple glutinous Thai rice variety Luem Pua (LP) in dextran sulfate sodium (DSS)-induced ulcerative colitis (UC) in rat and the possible cholinomimetic effects of the extract.

Methods: The effect of LP extract $(0.5,1$, or $1.5 \mathrm{mg} / \mathrm{ml}$ final concentration) on ileum contraction was tested using isolated guinea pig ileum. Certain agonists (acetylcholine, tetramethylammonium, and clonidine) and antagonists (hexamethonium chloride and atropine) were studied to determine the cholinomimetic effect of the extract. The effects of LP extract ( $5 \mathrm{~g} / \mathrm{kg} /$ day) in DSS-induced UC model (drinking water was replaced with $3 \%$ DSS in water for 7 days) in rat were evaluated. On each day of treatment, the change of disease activity index (DAI) was recorded. At the end of the experiments, rats were terminated and disease severity expressed as DAI, colon length, and spleen weight were determined.

Results: LP extract at the concentration of $0.5,1$, and $1.5 \mathrm{mg} / \mathrm{ml}$ (final concentration) could contract the ileum in a dose-dependent manner and be blocked completely by atropine. Oral administration of LP extract could significantly attenuate the severity of DSS-induced UC as seen by the reduction of DAI, colon length, and spleen weight.

Conclusion: Results in isolated guinea pig ileum suggest that LP might contain active substance that could activate muscarinic receptors. In addition to antioxidant activity, through activation of muscarinic receptor, might explain the protective effects of LP extract against DSS-induced UC in rats.

Keywords: Luem Pua rice, Muscarinic effect, Ulcerative colitis, Dextran sulfate sodium, Disease activity index.

(C) 2021 The Authors. Published by Innovare Academic Sciences Pvt Ltd. This is an open access article under the CC BY license (http://creativecommons. org/ licenses/by/4.0/] DOI: http://dx.doi.org/10.22159/ijap.2021.v13s1.Y0029. Journal homepage: https://innovareacademics.in/journals/index.php/ijap

\section{INTRODUCTION}

Inflammatory bowel disease (IBD) is characterized by chronic inflammation of the digestive tract and the two main subtypes of IBD are Crohn's disease (CD) and ulcerative colitis (UC). Although the etiology of IBD is still unknown, many are postulated and seem to be multifactorial disease. From many previous studies, one of the most pathogenesis of IBD is associated with an autonomic imbalance and up to $35 \%$ of patients with UC exhibit autonomic dysfunction with impaired efferent vagus nerve activity and/or impaired of parasympathetic nerve functions related with inflammation $[1,2]$. Parasympathetic nerve activity in gastrointestinal (GI) tract control of GI movement is also suggested to have role in the control of cytokine functions. Increasing of pro-inflammatory cytokines can be inhibited by activation of cholinergic receptors on intestinal mucosal epithelial cells and could attenuate cytokine activities in dextran sulfate sodium (DSS)-induced colitis [3]. Moreover, rivastigmine which is a cholinesterase inhibitor could alleviate experimentally induced colitis in mice and rats by suppressing the production of pro-inflammatory cytokine (tumor necrosis factor- $\alpha$, interleukin (IL)-1 $\beta$, and IL-6) [4]. In addition, under inflammatory conditions, activation of the cholinergic anti-inflammatory pathway through muscarinic receptors on epithelial cells is suggested to help maintain epithelial barrier function and protects against cytokine-induced barrier dysfunction [5]. Hence, increasing intestinal cholinergic anti-inflammatory pathway can alleviate the inflammation and has been identified as one of a potential target for IBD drug [6]. Thai dark-purple glutinous rice variety Luem Pua (LP) (Oryza sativa Linn, var. LP), a pure-line selection carried out by Phitsanulok Rice Research Center, is enriched with flavonoids and total antioxidant higher than many other black rice [7]. Anti-oxidative and also memory-enhancing effects of LP extract have been shown in both cell culture and mice [8]. As LP extract could alleviate the memory impairment effect of a muscarinic antagonist, it might be the case that, in addition to anti-oxidant effect, LP might have cholinomimetic activity. Therefore, the purpose of this study was to investigate the possible cholinomimetic effects of the LP extract in isolated Guinea pig ileum and the effects of the extract in DSS-induced UC in rat model.

\section{METHODS}

\section{Plant extract}

The aqueous LP extract was prepared as described earlier [8]. In brief, LP rice, authenticated by the Phitsanulok Rice Research Center, Wang Thong, Phitsanulok, Thailand, was soaked with hot water for $5 \mathrm{~min}$, filtered and lyophilized. The percentage yield of the LP extract was calculated to be $2.16 \%$. Dried LP extract was stored at $4{ }^{\circ} \mathrm{C}$ and freshly dissolved in distilled water before used.

\section{Animals}

Male guinea pig and male Wistar rats (6 weeks old, 250-300 g body weight) were purchased from the National Laboratory Animal Center, Mahidol University, Thailand, and Nomura Siam International Co., Ltd, Pathumwan, Bangkok, Thailand. All animals were housed in an animal room maintained at constant temperature $\left(23-25^{\circ} \mathrm{C}\right)$ with a 12:12 h light:dark cycle. Food and water were available ad libitum. All animals were acclimatized to the laboratory room and handling for 1 week before the start of the experiments. All experiments were approved by the Animal Ethics Committee, Khon Kaen University, Thailand, and record number ACUC-KKU-21/2560, reference number 0514.1.75/30. 
Bioassay of cholinergic activity of LP extracts using isolated guinea pig ileum

The experiment was performed to assess the effect of LP extract on ileum contraction using isolated ileum of guinea pig [9]. Male guinea pig was killed and the ileum was rapidly removed and transferred to a dish containing Tyrode's solution aerated with $95 \% \mathrm{O}_{2}$ and $5 \% \mathrm{CO}_{2}$, at $37^{\circ} \mathrm{C}$. Ileum was cut about $2 \mathrm{~cm}$ long and placed in a $25 \mathrm{ml}$ organ bath which contain Tyrode's solution. One end of ileum was connected to tissue holder and the other end was tied with a thread, inserted through a transmural electrode connected to an electrical stimulator, and connected to Grass FT03 force displacement transducer. The contractile responses of the ileum were recorded to measure isometric contraction using polygraph (Grass Instruments Co., Quincy, Mass, U.S.A). Electrical stimulation and certain chemical substances were used in the study. Agonists (acetylcholine, tetramethylammonium [TMA] and clonidine) and antagonists (hexamethonium chloride and atropine) or LP extract at $0.5,1$, or $1.5 \mathrm{mg} / \mathrm{ml}$ (final concentrations) were tested. The change of ileum tension was recorded for $5 \mathrm{~min}$, after which the preparations were rinsed 2 times and allowed to recover before the next experiment.

\section{DSS-induced IBD in rat}

The induction of IBD in rats through administration of DSS as previously described [10]. Rats were divided into five groups of six rats. Animals were force-fed with distilled water (as the control), LP extract (5 g/kg), or sulfasalazine $(300 \mathrm{mg} / \mathrm{kg})$ once daily for the whole experimental period (14 days). On day 8 to day 14 of treatment, $2 \mathrm{~h}$ after being forcefed, the animals received 3\% DSS in drinking water. On each day, the symptoms indicating the severity of colitis, including body weight loss, stool consistency, and the presence of stool blood were recorded and expressed as disease activity index (DAI) [11]. On day 15, all animals were sacrificed by deep ether anesthesia and the colons and spleens were removed and the colons length $(\mathrm{cm})$ and spleen weight $(\mathrm{mg})$ were measured.

\section{Determination of DAI}

Three parameters (body weight loss, stool consistency, and the presence of stool blood) were observed each day and scored as described earlier [11]. Grading of the changes were made using: Five grades of weight loss (0: either a gain of weight or no weight loss; 1 : $1-5 \%$ loss; 2 : $5-10 \%$ loss; $3: 10-20 \%$ loss; and 4 : more than $20 \%$ loss), three grades of stool consistency (0: normal; 2: loose; and 4: diarrhea), and three grades of stool blood (0: negative; 2: blood-positive; moderate, and 4: blood-positive; severe). Summation of the scores of all three parameters was expressed as DAI.

\section{Statistical analysis}

All results were presented as mean \pm SEM. Statistical comparisons between groups were analyzed with one-way analysis of variance followed by post hoc Tukey's test. The results were considered to be statistically significant at $\mathrm{p}<0.05$

\section{RESULTS}

\section{Effect of LP extract on isolated ileum of guinea pig}

Electrical stimulation ( 60 volts) and acetylcholine $(3 \mu \mathrm{g} / \mathrm{ml}$, final concentration) were used as the standard control treatment. LP extract, at all doses tested $(0.5,1$, or $1.5 \mathrm{mg} / \mathrm{ml})$, could induce the contraction of the ileum (Fig. 1a) and forces of the ileum contraction, as percentage of the electrical stimulation, were $75.62 \pm 7.37,123.26 \pm 17.73$, and $126.75 \pm 12.34$, respectively (Fig. 1b).

Effects of various agonists and antagonists on the LP extractinduced ileum contraction

Nicotinic receptor agonist/antagonist and alpha ${ }_{2}$ adrenergic receptor agonist

TMA $12.5 \mathrm{mM}$, a nicotinic receptor agonist, and hexamethonium chloride (C6) $40 \mathrm{mg} / \mathrm{ml}$, a nicotinic receptor antagonist, were tested.

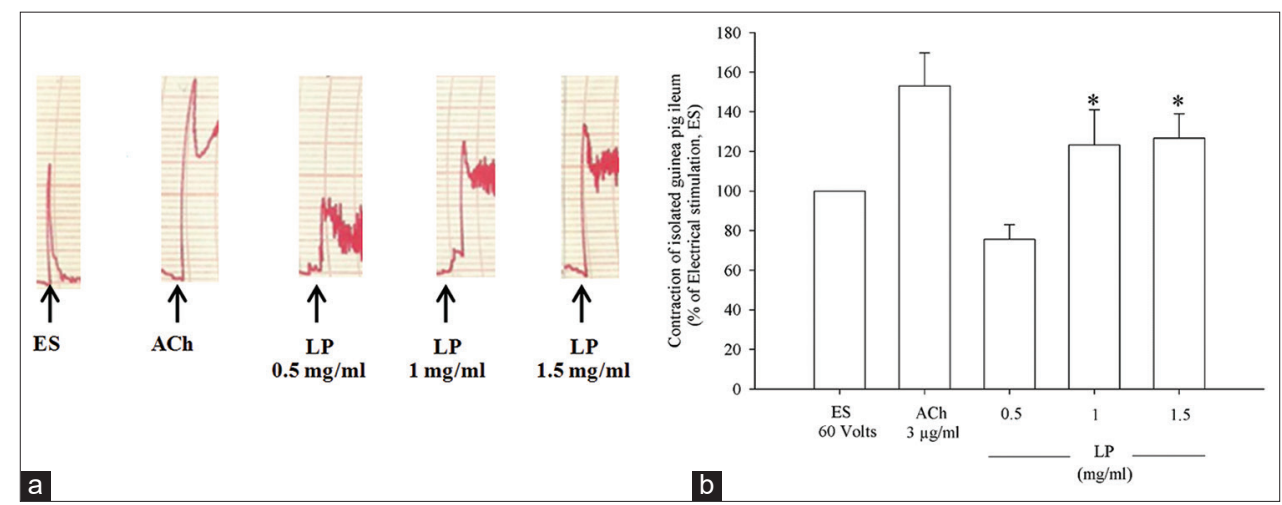

Fig. 1: (a) Tracings show responses of isolated guinea pig ileum to various stimuli and (b) contraction of guinea pig ileum induced by electrical stimulation (ES) at 60 volts, acetylcholine (ACh) $3 \mu \mathrm{g} / \mathrm{ml}$ or Luem Pua (LP) extract at $0.5,1$, or $1.5 \mathrm{mg} / \mathrm{ml}$ were expressed as of percentage of ES (mean \pm SEM). *Significant different when compared to LP extract at $0.5 \mathrm{mg} / \mathrm{ml}$

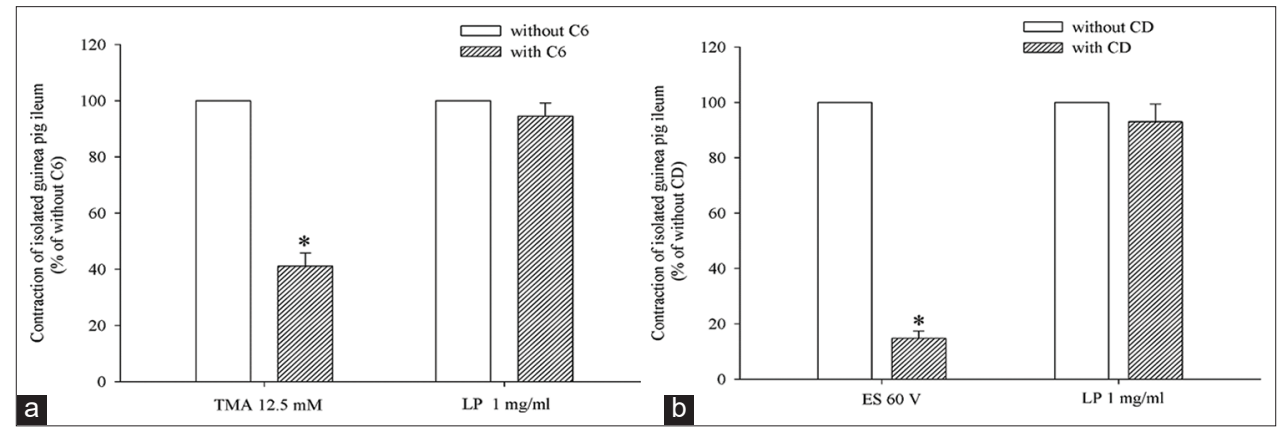

Fig. 2: The contraction of guinea pig ileum induced by tetramethylammonium (TMA) and LP extract with or without C6 expressed as percentage of the contraction without $\mathrm{C6}$ (a) and ES and LP extract with or without CD expressed as percentage of the contraction without CD (b). *Significant different when compared to TMA without C6 or ES without CD 
The contraction induced by TMA was clearly seen and preincubation with $\mathrm{C} 6$ resulted in a significant decrease of TMA response. However, C6 had no effects on the ileum contraction caused by $1 \mathrm{mg} / \mathrm{ml}$ of LP extract (Fig. 2a).

Adding $125 \mu \mathrm{g} / \mathrm{ml}$ clonidine (CD) into the bath significantly reduced the contraction of the ileum induced by ES since CD, an alpha ${ }_{2}$ agonist, reduces $\mathrm{ACh}$ release from cholinergic nerve terminal (Fig. 2b). Incubation with $\mathrm{CD}$ also had no effect on the ileum contraction caused by $1 \mathrm{mg} / \mathrm{ml}$ of LP extract.

\section{ACh and muscarinic receptor antagonist}

The ileum contraction induced by $3 \mu \mathrm{g} / \mathrm{ml}$ of ACh was completely inhibited by $2 \mu \mathrm{g} / \mathrm{ml}$ of atropine, a muscarinic receptor antagonist.

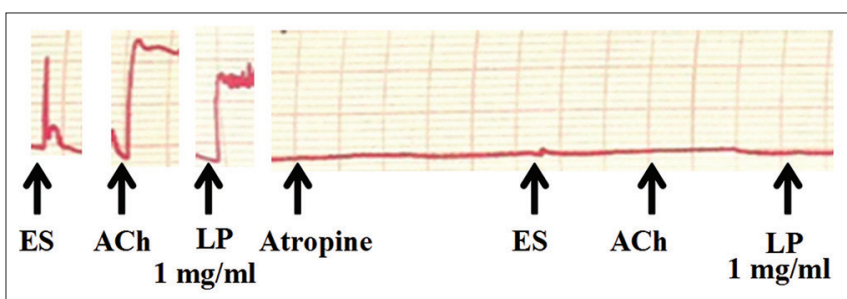

Fig. 3: The effect of atropine on isolated guinea pig ileum contraction induced by ES, ACh or LP extract. ES = Electrical stimulation 60 volts; ACh = Acetylcholine $3 \mu \mathrm{g} / \mathrm{ml}$;P = Luem Pua extract

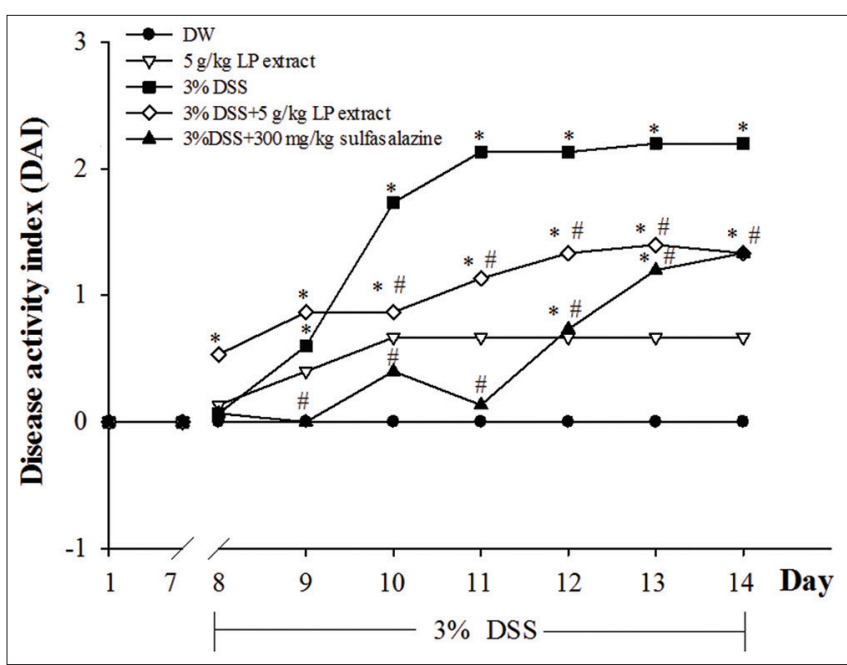

Fig. 4: Effect of LP extract on DAI score in DSS-induced UC in rats. Data were expressed as mean \pm SEM. *Significant different when compared to the control group; "Significant different when compared to the DSS group
Interestingly, atropine also completely abolished the effect of $1 \mathrm{mg} / \mathrm{ml}$ LP extract on isolated guinea pig ileum, indicating that LP extract might directly stimulate muscarinic receptor on the ileum tracing (Fig. 3).

\section{Effect of LP extract in DSS-induced UC in rat}

From day 8-day 14 (DSS period), rats that received DSS showed signs and symptoms of UC as seen by a significant increase in DAI when compared to the control (Fig. 4). Although rats that received LP extract at $5 \mathrm{~g} / \mathrm{kg} /$ day had mild loose stool, no significant effect on DAI was seen. Interestingly, pretreatment with LP extract $5 \mathrm{~g} / \mathrm{kg} /$ day or $300 \mathrm{mg} / \mathrm{kg}$ sulfasalazine could significantly reduce, although not completely reverse, the severity of DSS-induced UC when compare to the DSS group.

A significant decrease in colon length (Fig. 5a) and spleen enlargement (Fig. 5b) were observed in rats treated with DSS when compared to the control group. Interestingly, pretreatment with LP extract ( $5 \mathrm{~g} / \mathrm{kg} /$ day) or sulfasalazine $(300 \mathrm{mg} / \mathrm{kg} /$ day) was able to antagonize the effects of DSS on colon length and spleen weight to a comparable degree with the control group, suggesting that LP extract could ameliorate the severity of inflammation in DSS-induced UC in rats.

\section{DISCUSSION}

This study demonstrated that the aqueous extract of LP could contract ileum in a manner such as ACh and probably through the activation of muscarinic receptor as its effect was completely blocked by atropine. Administration of LP extract to rats treated with DSS could decrease the severity of colitis symptoms in all parameters observed.

In isolated guinea pig ileum, LP extract caused ileum contraction in a dose-dependent manner. Interestingly, the contraction of ileum induced by the extract was unable to antagonize by $\mathrm{C} 6$ or $\mathrm{CD}$, but completely inhibited by atropine. The results suggest that the action of LP extract might not be at the ganglion or presynaptic terminal, but directly at muscarinic receptors. Based on this mechanism, LP might have AChlike substance and improve memory [8] and modulate GI contraction through the activation of muscarinic receptor [12]. In addition, many biological active polyphenolic compounds were found in the LP extract including anthocyanins, ferulic acid, catechin, gallic acid, isoquercetin, quercetin, rutin, and tannic acid. Certain phenolic compounds were reported to have the ability to enhance GI contraction [13,14]. Although the exact mechanism is currently unknown, the impairment of parasympathetic nerve functions has been proposed as being involved with inflammation and pathogenesis of IBD [15]. Parasympathetic innervation of GI tract also plays a role in immune homeostasis by the regulation of local and systemic inflammation through muscarinic receptors and modulates inflammatory cytokine production by activation of the cholinergic anti-inflammatory pathway [16,17] and attenuate cytokine activities [4,5]. In this study, pretreatment of LP extract with DSS-induced UC in rat showed a significant decrease of DAI, the shortening of colon length, and the enlargement of spleen weight. It might be the case that LP extract stimulate muscarinic receptor in GI tract and help reduce the severity of inflammation and progression of

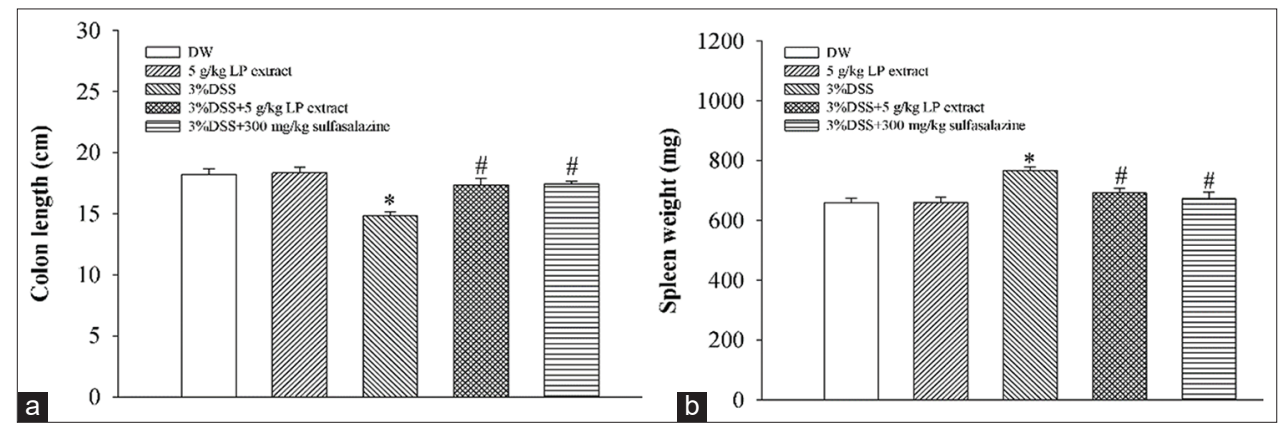

Fig. 5: Effects of LP extract and sulfasalazine on colon length (a) and spleen weight (b) in DSS-induced UC in rats. Data were expressed as mean \pm SEM. *Significant different when compared to the control group, "Significant different when compared to the DSS group 
DSS-induced UC. In addition to the cholinomimetic effect, LP extract is also rich in many biologically active polyphenolic compounds which are shown to be very active anti-oxidative substances. As oxidative stress is suggested to be involved in the pathogenesis of IBD [18], increasing anti-oxidant status by LP extract will reduce the severity of IBD.

\section{CONCLUSION}

The present findings show that LP extract attenuates the severity of DSS-induced UC in rats. The results from isolated ileum work suggest that the effect of LP extract is probably related, at least in part, to the modulatory effect of the extract on cholinergic activity of the gut. Studying the effects of LP extract on other colitis models and changing of gut microbiota profiles are in progress. Despite the exact mechanism of action, the present finding suggests that LP extract can be one of the candidates as a nutraceutical to help ameliorate the severity of the symptoms experienced in patients with UC.

\section{CONFLICTS OF INTEREST}

The authors declare that there are no conflicts of interest regarding the publication of this paper.

\section{REFERENCES}

1. Ji H, Rabbi MF, Labis B, Pavlov VA, Tracey KJ, Ghia JE, et al. Central cholinergic activation of a vagus nerve-to-spleen circuit alleviates experimental colitis. Mucosal Immunol 2014;7:335-47.

2. Di Giovangiulio $M$, Verheijden S, Bosmans G, Stakenborg N, Boeckxstaens GE, Matteoli G, et al. The neuromodulation of the intestinal immune system and its relevance in inflammatory bowel disease. Front Immunol 2015;6:590.

3. Kolgazi M, Uslu U, Yuksel M, Velioglu-Ogunc A, Ercan F, Alican I, et al. The role of cholinergic anti-inflammatory pathway in acetic acid-induced colonic inflammation in the rat. Chem Biol Interact 2013;205:72-80.

4. Shifrin H, Nadler-Milbauer M, Shoham S, Weinstock M. Rivastigmine alleviates experimentally induced colitis in mice and rats by acting at central and peripheral sites to modulate immune responses. PLoS One 2013;8:e57668.

5. Dhawan S, Hiemstra IH, Verseijden C, Hilbers FW, Te Velde AA, Willemsen LE, et al. Cholinergic receptor activation on epithelia protects against cytokine-induced barrier dysfunction. Acta Physiol
(Oxf) 2015;213:846-59.

6. Brinkman DJ, ten Hove AS, Vervoordeldonk MJ, Luyer MD, de Jonge WJ. Neuroimmune interactions in the gut and their significance for intestinal immunity. Cells 2019;8:670.

7. Suwannalert P, Rattanachitthawat S. High levels of phytophenolics and antioxidant activities in Oryza sativa unpolished Thai rice strain of Leum Phua. Trop J Pharm Res 2011;10:431-6.

8. Srisuwan S, Arkaravichien T, Mahatheeranont S, Puangsombat P, Seekhaw P, Noenplab AN, et al. Effects of aqueous extract of unpolished dark purple glutinous rice var Luem Pua on ROS in SK-N-SH cells and scopolamine-induced memory deficit in mice. Trop J Pharm Res 2015;14:1635-41.

9. Ochillo RF, Tsai CS, Tsai MH. Mechanism of action of muscarine on the longitudinal muscle of the guinea-pig isolated ileum. Br J Pharmacol 1981;72:225-32.

10. Pengkumsri N, Sivamaruthi BS, Sirilun S, Suwannalert P, Rodboon T, Prasitpuriprecha $\mathrm{C}$, et al. Dietary supplementation of Thai black rice bran extract and yeast beta-glucan protects the dextran sodium sulphate mediated colitis induced rat. Rsc Adv 2017;7:396-402.

11. Nagib MM, Tadros MG, ElSayed MI, Khalifa AE. Anti-inflammatory and anti-oxidant activities of olmesartan medoxomil ameliorate experimental colitis in rats. Toxicol Appl Pharmacol 2013;271:106-13.

12. Fujii W, Hori H, Yokoo Y, Suwa Y, Nukaya H, Taniyama K, et al. Beer congener stimulates gastrointestinal motility via the muscarinic acetylcholine receptors. Alcohol Clin Exp Res 2002;26:677-81.

13. Edwards CA, Havlik J, Cong W, Mullen W, Preston T, Morrison DJ, et al. Polyphenols and health: Interactions between fibre, plant polyphenols and the gut microbiota. Nutr Bull 2017;42:356-60.

14. Badary OA, Awad AS, Sherief MA, Hamada FM. In vitro and in vivo effects of ferulic acid on gastrointestinal motility: Inhibition of cisplatininduced delay in gastric emptying in rats. World $\mathrm{J}$ Gastroenterol 2006; $12: 5363-7$.

15. Ghia JE, Blennerhassett P, Collins SM. Impaired parasympathetic function increases susceptibility to inflammatory bowel disease in a mouse model of depression. J Clin Invest 2008;118:2209-18.

16. Meroni E, Stakenborg N, Viola MF, Boeckxstaens GE. Intestinal macrophages and their interaction with the enteric nervous system in health and inflammatory bowel disease. Acta Physiol (Oxf) 2019;225:e13163.

17. Rosas-Ballina M, Tracey KJ. Cholinergic control of inflammation. J Intern Med 2009;265:663-79.

18. Guan G, Lan S. Implications of antioxidant systems in inflammatory bowel disease. Biomed Res Int 2018;2018:290179. 